\title{
ロボット指のための小型触覚センサの開発*
}

\author{
伊藤彰人*1, 过内伸好*2, 小泉孝之孚 \\ 大島裕 子*2, 野尻 芳 郎*3, 土屋 陽太郎*4 \\ 平間直 道 ${ }^{* 5}$, 黒木史 郎 ${ }^{* 5}$
}

\section{Development of a Small Tactile Sensor for Robot Finger}

\author{
Akihito ITO*6, Nobutaka TSUJIUCHI, Takayuki KOIZUMI, \\ Hiroko OSHIMA, Yoshiro NOJIRI, Yotaro TSUCHIYA, \\ Naomichi HIRAMA and Shiro KUROGI \\ ${ }^{* 6}$ Department of Mechanical Engineering, Graduate School of Engeering, Doshisha University, \\ 1-3 Tatara-miyakodani, Kyotanabe-shi, Kyoto, 610-0332 Japan
}

\begin{abstract}
This paper presents a new tactile sensor that can detect the vertical force and the shear force. This proposed tactile sensor detects an applied force as a change in electrical resistance in strain gauges attached to the surface. For outputs of this proposed sensor, the interaction occurs structurally, and the hysteresis also occurs since the force applying on the sensor is detected by the strain gauge attached to the surface. However, since the effects of the hysteresis are small and difficult to correct, we disregard the hysteresis, and only correct the interaction. Measurement of the vertical and shear forces applying on this proposed tactile sensor becomes possible after correcting the interaction. The experimental results show that three dimensional forces can measure using this proposed tactile sensor. This proposed tactile sensor has simple structure. Therefore, because of this structure, this tactile sensor can be made easily and realized as small size.
\end{abstract}

Key Words: Sensor, Measurement, Mechatronics and Robotics, Finite Element Method, Tactile Sensor, Strain Gauges, Robot Fingers

\section{1. 粕 言}

現在, ロボットには, 工業のみならず, 高度な作業 を行う介護・福祉機器などに活躍の場が広がることが 期待されている(1)(2). ロボットの適用分野の拡大に伴い, ロボットハンドの操作には, 物体を損傷させることな く, かつ滑らないように, 安定した状態で把持するな ど, きめ細やかなマニピュレーションが必要であるる((3)(4). このような高度な動作を実現するためには，口ボット ハンドの表面に作用する圧力だけでなく, 表面に作用 する滑り力を同時に検出する必要がある( ${ }^{(9)}$.このこと からロボットハンドには三軸触覚センサが必要不可欠 となり三軸触覚センサへの期待も高まっている.

これまで様々な三軸触覚センサの研究, 開発が行わ れてきた. 金属梁の変形を歪ゲージにより計測するセ

* 原稿受付 2006 年 1 月 20 日.

*1 正員, 同志社大学大学院工学研究科 (画 610-0332 京田辺市 多々羅都谷 1-3).

*2 正員, 同志社大学工学部.

*3 センサ・デバイス開発研究所( $182-0012$ 調布市深大寺東 町 5-23-3).

*4 正員, (株)テック技販 (釆611-0033 宇治市大久保町西ノ端 1-22).

*5 東芝電子エンジニアリング(株) (丣 235-8522 横浜市磯子区 新杉田町 8).

E-mail : etfl302@mail4.doshisha.ac.jp
ンサ(の)、マーカーを埋め込んだ透明弾性体を CCD カメ ラで撮影し弾性体の変形情報から力を計測する光学式 触覚センサ(7), 弾性体表面に取り付けられた一次励磁 コイルの位置を弾性体の反対側に取り付けられた二次 誘電コイルによって検出することにより弾性体の変形 を検出する電磁誘導の原理を用いた三軸触覚センサ(の) などが開発されている.しかし，金属梁を用いるセン サでは構造が複雑になり, 光学式触覚センサでは映像 装置が必要であるため小型化が困難である(5). また, 電磁誘導の原理を用いた三軸触覚センサは小型化が可 能であるが, 精度, 時間応答特性等の課題が残されて いる.

そこで本研究では, 歪ゲージを受感素子として用い た小型化が可能な触覚センサを提案する. 歪ゲージを 用いた触覚センサは (i) 精度が良く直線性が良い，（ii） 温度変化による影響が少ない，（iii）変位量が極めて 小さく静的現象, 動的現象の測定が可能などの利点が ある ${ }^{(8)}$. しかし, 歪ゲージを用いた三軸触覚センサの 小型化に関してはあまり議論がなされてこなかった. そこで，まず三軸触覚センサの新しい構造を提案し， 有限要素解析により各軸方向の力が計測可能であるこ と, 及び固有振動数が十分に高いことを確かめる. 次 
に, 三軸触覚センサを試作し, 各軸方向の出力值の特 性を計測し，本センサの評価を行う．試作したセンサ は長さ $25[\mathrm{~mm}]$, 幅 $25[\mathrm{~mm}]$, 高さ $10[\mathrm{~mm}]$ の大きさであ り，機械的に構造が単純であるため製作が容易であり， 小型化も可能である.

\section{2. 三軸触賞センサの構造及び出力原理}

三軸触覚センサの形状を図 1 に示寸. 触覚センサの 材料は黄銅（C2801）であり，上部の板が 4 本足で支え られた構造となっている. 4 本の足の底面を本センサ の岡性より高い鋼材 (SS400) に接着剂により固定され ている.触覚センサの大きさは長さ $25[\mathrm{~mm}]$, 幅 $25[\mathrm{~mm}]$, 高さ $10[\mathrm{~mm}]$, 厚さ $0.5[\mathrm{~mm}]$ である. 本センサは作用す る力を表面に貼られた歪ゲージの電気抵抗変化として 検出する．Z 軸方向に作用する力を計測するための歪 ゲージは半径方向の歪を計測するダイアフラムゲージ であり，図2(a)に示寸上面板の裏側の a b b c c，dの箇

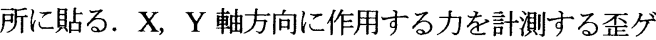
ージは箔歪ゲージであり，図2(b)に示す足表面の a, b,

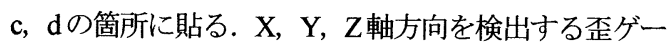
ジには, 各軸ごとに図3に示すブリッジ回路が組まれ， 差動電圧を計測することで作用力を計測している.こ れにより本センサは垂直力とせん断力を計測すること ができる. 4本足の上下折り曲げ部にはくびれをつけ, $\mathrm{X}$ 軸方向もしくはY 軸方向に力が作用した時に $\mathrm{Y}$ 軸方 向もしくはX軸方向の2本の足に生じる歪を小さくし， 相互干渉を小さくしている。 また上面には, 直径 $5.0[\mathrm{~mm}]$, 厚さ $1.0[\mathrm{~mm}]$ のゴム板が接着されており, Z 軸方向の作用力が上面板内で等分布になるようにして いる.

\section{3. 解析による検証}

3.1 センサの計瀴値の検証 前章に示した三軸触 覚センサが力を計測可能であることを検証するため有 限要素法を用いて歪ゲージの変位量の解析を行う。 シ ミュレーションには, 構造解析ソフトウェア (UGS PLMソリューションズ(株)NX Nastran，Ver.3.0）を用い た. 本研究で使用した三軸触覚センサの有限要素モデ ルを図4に示す. 本モデルは節点数 2323, 要素数 2012 で構成されている有限要素モデルである. 本モデルの 縦弾性係数は $1.0 \times 10^{5}\left[\mathrm{~N} / \mathrm{mm}^{2}\right]$, 横弾性係数は $3.7 \times 10^{4}\left[\mathrm{~N} / \mathrm{mm}^{2}\right]$, ポアソン比は 0.35 とした. これらは, 実際のセンサの材料である黄銅 (C2801) の物性值であ る.
解析方法は，4 本足の底面の節点の変位を拘束し， ゴム板の貼られている部分の合力が各方向の作用力に なるように一様に負荷した，そして，各節点の変位量 から負荷時と無負荷時の各歪ゲージの長さを計算する ことで，作用力と歪量の関係を検証した。 なお，三軸 触覚センサとしての構造の有効性を検証するために解 析を行ったので, 本解析では上面に貼り付けたゴムに ついては考慮していない.

せん断力方向に力を作用させたときの作用力と歪 の関係を図 5 に示し, 垂直力方向に力を作用させたと きの作用力と歪の関係を図 6に示す. せん断力方向に 力を作用させた場合には出力值に良い直線性が得られ た. 垂直力方向に力を作用させた場合には上面板の表 面の伸びには非直線性が現れている。 しかし，センサ への最大負荷が小さいことより，変形量は微小となる ため, 直線で近似しても問題はないと考えられる. こ れにより，各方向の作用力に対して歪ゲージによる力 の計測が可能であることが示せた.

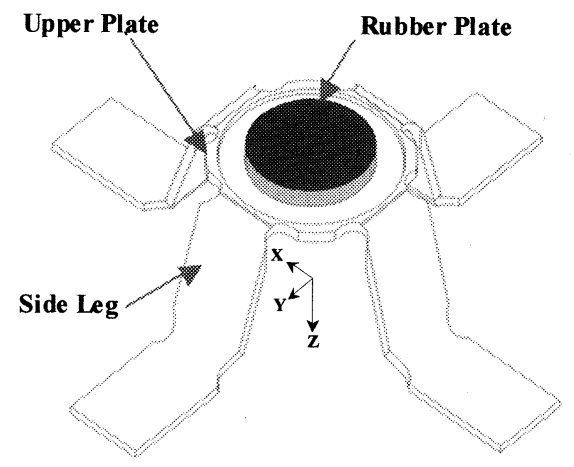

Fig. 1 The structure of tactile sensor

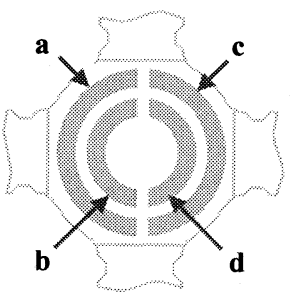

(a) Upperplate

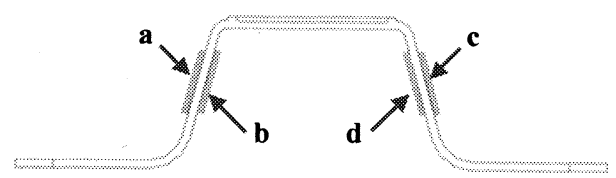

(b) Side legs

Fig. 2 The position of strain gauges 


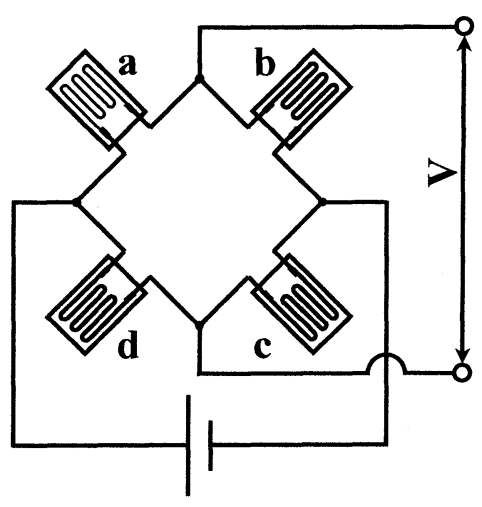

Fig. 3 The full bridge circuit

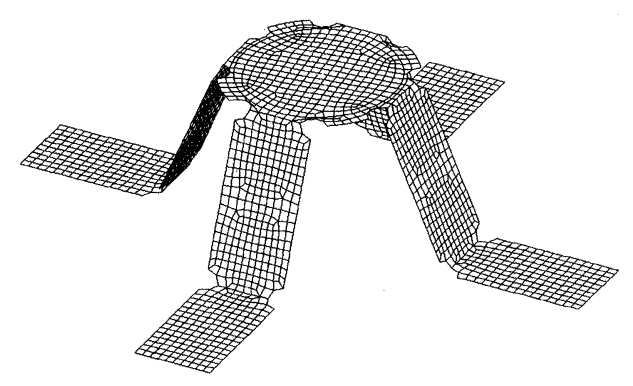

Fig. 4 The finite element model of sensor

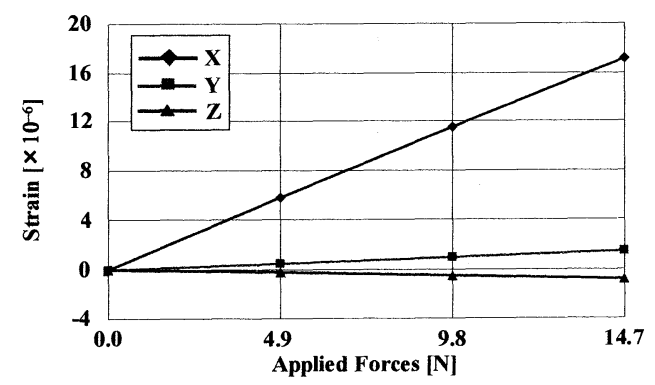

Fig. 5 The analysis result of shear force

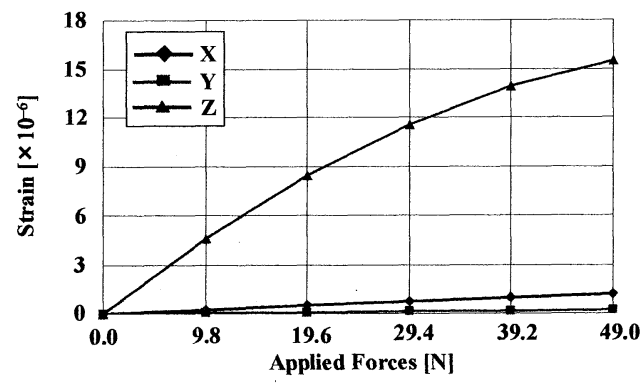

Fig. 6 The analysis result of vertical force
3.2 動特性の検証 前節同様に構造解析ソフトウ エア (UGS PLM ソリューションズ(株)NX Nastran, Ver.3.0）を用いて固有値解析を行った. その結果を表 1 に示す. 前節同様に 4 本足の底面の変位を拘束して 解析した. 1 次と 2 次のモード形状は上面板が X軸も しくは Y 軸方向に振動するモードであり，3 次のモー ド形状は上面板が上下方向に振動するモードであり, 4 次のモ一ド形状は上面板が回転するねじれモードであ る.この結果より，本センサの固有振動数は $1000[\mathrm{~Hz}]$ 以上であり，ロボットハンドに搭載しても問題なく動 的な力の計測が可能である.

Table 1 The dynamic characteristics of sensor

\begin{tabular}{c|c}
\hline \hline Natural mode & Eigenfrequency $[\mathrm{Hz}]$ \\
\hline The first mode & $8.601 \times 10^{3}$ \\
\hline The second mode & $8.604 \times 10^{3}$ \\
\hline The third mode & $1.338 \times 10^{4}$ \\
\hline The forth mode & $1.507 \times 10^{4}$ \\
\hline
\end{tabular}

\section{4. 実 験}

試作した触覚センサを用いて出力值を検証するた めの実験を行った.

4.1 実験方法 センサに力を作用させた時の出力 值の計測実験を行う。本研究における実験では, 共和 電業製のオンライン型コンディショナ(MCE-24)を動歪 測定器として用いて，作用力に対する歪值の計測を行 う。以下に示す $2 つ 0$ 条件に対して実験を行う.

条件(a) X, Y, Z軸それぞれの方向に力を作用させる.

$\mathrm{X}, \mathrm{Y}$ 軸方向の作用力は，0.0[N]から 14.7[N]ま で4.9[N]ずつ増加させ, その後 4.9[N]ずつ减少 させた：Z軸方向の作用力は， $0.0[\mathrm{~N}]$ から 49.0[N]まで 9.8[N]ずつ増加させ, その後 9.8[N] ずつ除去する. 各方向力を作用させ，除去す るまでの過程を 3 回続けて行う.

条件(b) $\mathrm{X}, \mathrm{Y}, \mathrm{Z}$ 軸方向に同時に力を作用させる. 作 用力は条件(a)の作用力の組み合わせとする.

条件(a)は本センサの出力值の特性を検証するため の実験である.この実験により本センサの特性である 定格出力値, 非直線性, ヒステリシス, 相互干渉性, 繰り返し性を求めることができ, 各計測值より本セン サの精度を算出できる. 条件(b)は垂直力とせん断力が 同時に計測可能であるかを検証するための実験である.

実験装置には，図7に示す垂直力とせん断力を作用 させることが可能な負荷実験機を用いる.この装置は 
センサから離れた点に重力を利用した荷重を加えるこ とでセンサに任意のカベクトルを作用させる装置であ る. センサの表面には図 8 に示寸黄銅の円盤を接着す る. せん断力を作用させる場合には図 9 に示すように この円盤にワイヤーを桖じで固定し，滑車を介し鍾を 載せる.このようにしてセンサにせん断力を作用させ る. 垂直力を作用させる場合にはこの円盤の上に球体 を載せ，図10に示すように錘を載せる.このようにし てセンサに垂直力のみを作用させる．X，Y，Z軸方向 に同時に力を作用させる場合は，上記の方法を組み合 わせることによりセンサに三軸力を作用させる.

4.2 実験結果条件(a)の結果を図 11-13 に示寸。 この結果より得られた本センサの特性を表 2 に示す. 非直線性，ヒステリシス，繰り返し性は各方向の定格 出力値に対する百分率 $[\% \mathrm{RO}$ ]で示し，相互干渉は作用 力方向の出力值との百分率で示した．また，各特性は 実験で得られた值の最大值とした. 本センサの各成分 の出力は, 各方向の作用力に対してほぼ線形関倸にあ り, ヒステリシスと相互干渉, 繰り返し性の補正を行 う必要があることがわかる.

条件(b)の結果を図 14 に示寸. 図 14 は, 条件(b)の結 果の一例であり，X軸，Y 軸方向に 9.8[N]の力を作用さ

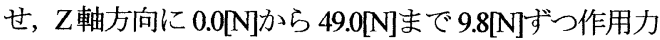
を増加させた時の実験結果である。これにより，セン サに三軸力が同時に作用した場合においても出力值は 作用力に対して線形性があり, 相互干渉が生じている ことがわかる. 従って, 相互干渉を補正する必要があ る.

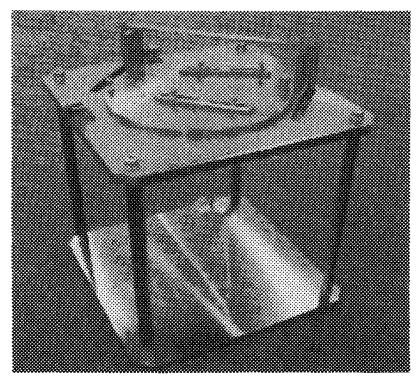

Fig. 7 The experimental equipment

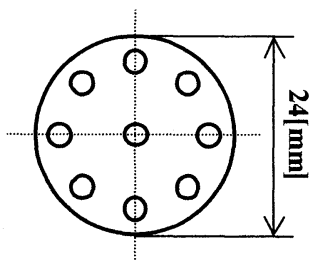

Fig. 8 The shape of the disk

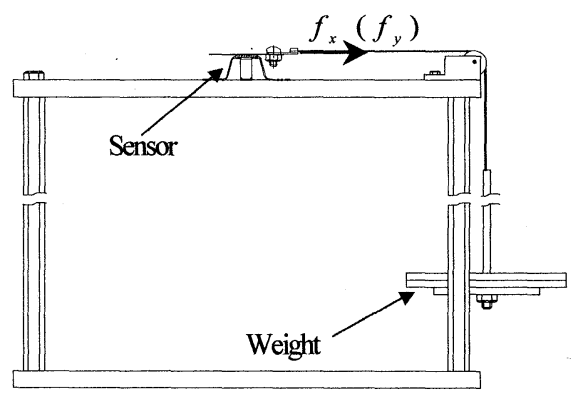

Fig. 9 The applied method of shear force

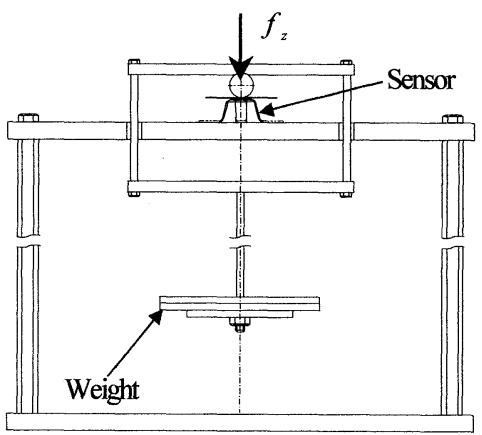

Fig. 10 The applied method of vertical force

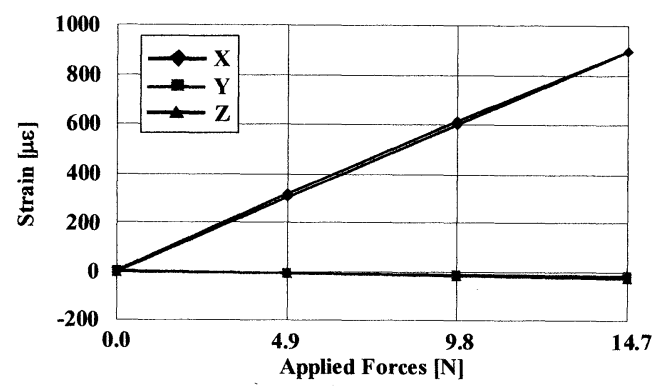

Fig. 11 The outputs of sensor of $\mathrm{X}$-axis direction forces

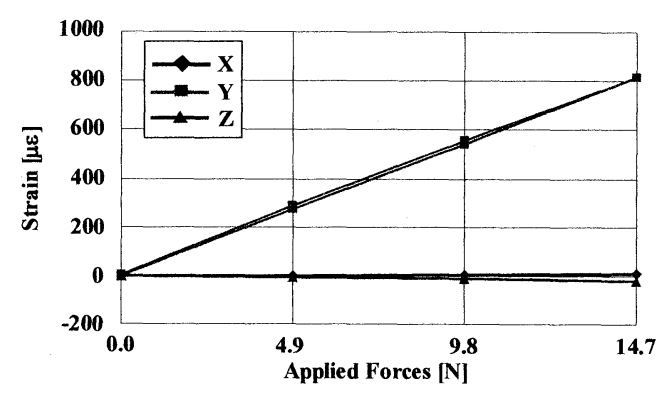

Fig. 12 The outputs of sensor of Y-axis direction forces 


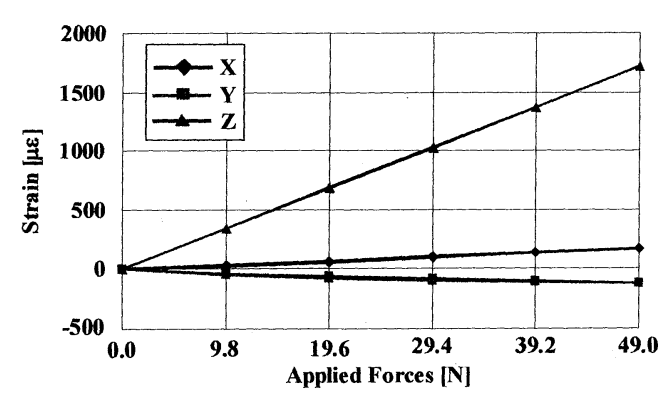

Fig. 13 The outputs of sensor of Z-axis direction forces

Table 2 The characteristic of sensor

\begin{tabular}{c|c|c}
\hline & $\mathrm{X}, \mathrm{Y}$-axis & Z-axis \\
\hline Nonlinearity [\%RO] & 3.5 & 1.5 \\
\hline Hysteresis [\%RO] & 3.6 & 1.3 \\
\hline Repeatability [\%RO] & 0.8 & 0.7 \\
\hline Interaction [\%] & 8.0 & 16.0 \\
\hline
\end{tabular}

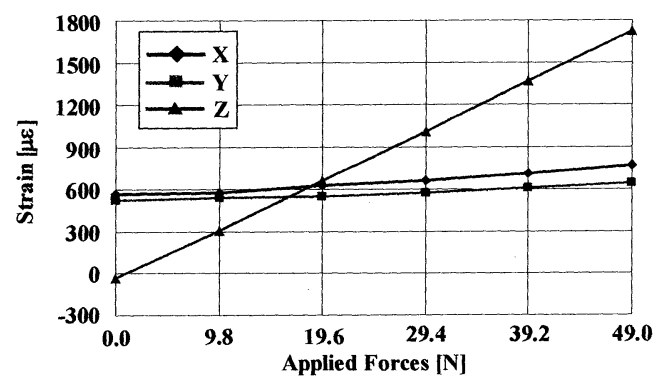

Fig. 14 The outputs of sensor of three-axes forces

4.3 出力值の補正方法, 及び補正結果 ヒステリ シス，繰り返し性は影響が小さく信号処理による補正 が困難であることより無視し，相互干涉補正のみを行 う.ここで, 相互干渉により生じる出力值に注目する.

図 15 にZ方向に力を作用させた時, 相互干涉の影響か ら生じる X, Y方向の出力を示し, 図 16 に図 14 の結 果の $\mathrm{X}, \mathrm{Y}$ 方向の出力值を示す.

図 15，16より，干渉により生じる出力値にも作用 力に対してほぼ線形関係があることが確認できる.よ って，相互干渉により生じる出力值を予測することが 可能なことから式(1)が導かれる.

$$
\begin{aligned}
& \varepsilon_{x}=c_{11} f_{x}+c_{12} f_{y}+c_{13} f_{z} \\
& \varepsilon_{y}=c_{21} f_{x}+c_{22} f_{y}+c_{23} f_{z} \\
& \varepsilon_{z}=c_{31} f_{x}+c_{32} f_{y}+c_{33} f_{z}
\end{aligned}
$$

すなわち, 式(2) となる.

$$
\boldsymbol{\varepsilon}=\left(\begin{array}{l}
\varepsilon_{x} \\
\varepsilon_{y} \\
\varepsilon_{z}
\end{array}\right)=\left(\begin{array}{lll}
c_{11} & c_{12} & c_{13} \\
c_{21} & c_{22} & c_{23} \\
c_{31} & c_{32} & c_{33}
\end{array}\right)\left(\begin{array}{l}
f_{x} \\
f_{y} \\
f_{z}
\end{array}\right)=\boldsymbol{C} \boldsymbol{F}
$$

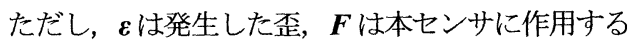
力, $\boldsymbol{C}$ は歪コンプライアンス行列である. よって, キ ヤリブレーションにより歪コンプライアンス行列を求 めれば，歪コンプライアンス行列の逆行列 $\boldsymbol{C}^{-1}$ を用い て歪ゲージの出力から相互干渉を補正したセンサに作 用する力 $\boldsymbol{F}$ を求めることができる.

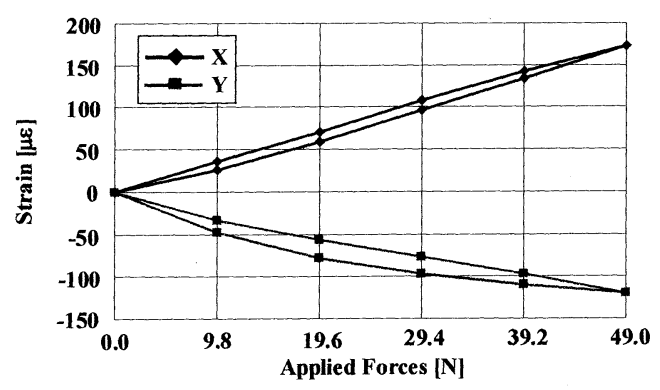

Fig. 15 The $\mathrm{X}$-axis and $\mathrm{Y}$-axis direction outputs of sensor of Z-axis direction forces

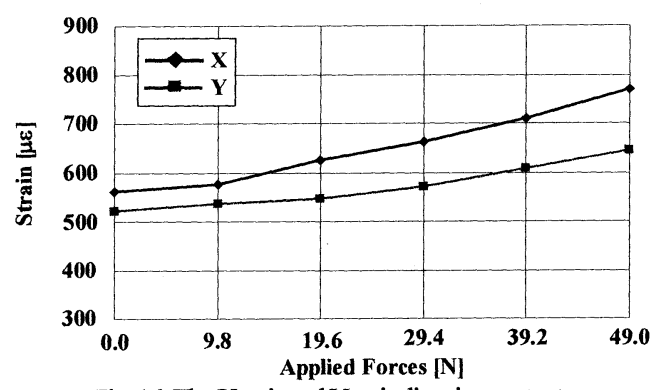

Fig. 16 The $\mathrm{X}$-axis and $\mathrm{Y}$-axis directions output of sensor of three-axes forces

キャリブレーションにより求めた試作したセンサ の歪コンプライアンス行列 $\boldsymbol{C}$ を以下に示す.

$$
C=\left(\begin{array}{ccc}
1566.5 & 27.0 & 74.4 \\
60.5 & 1823.6 & -20.2 \\
-451.2 & -383.2 & 2882.4
\end{array}\right)
$$

この歪コンプライアンス行列を用いて相互干涉補正を 行った結果を表 3 に示す. 表 3 には, 作用力と相互干渉 補正後の計測值との誝差を定格值 (X, Y 方向; 14.7[N], Z 軸方向； 49.0[N]）に対する百分率で示した. 相互干 渉補正後の計測值には, 補正不可能な誤差としてセン サ素子の出力值の非直線性, ヒステリシス, 繰り返し 
性により生じる誤差が含まれる．よって，本センサの 各方向の精度 $E_{r}$ は式(4)により求まる.

$$
E_{r}=\sqrt{E_{1}^{2}+E_{2}^{2}+E_{3}^{2}}
$$

ただし， $E_{1}$ は非直線性， $E_{2}$ はヒステリシス， $E_{3}$ は繰 り返し性である。一般的には式(4)に零点の温度影響, 出力の温度影響も含めて用いるが，本実験では室内に 使用を限っていることと，歪ゲージが接着剤で覆われ ていることにより温度影響は小さいと考え現段階では 考慮しなかった.このことより本センサの精度は, X, Y 軸方向では 5.1[\%RO], Z軸方向では 2.1[\%RO]となる ここで, 表 3 に示した誤差は, この精度内であること より, 本センサの計測值の相互干渉補正の有効性を示 すことができた.これにより，試作した本センサは， 垂直力，せん断力を計測可能であることが示せた．ま た,この実験で得られた本センサの仕様を表 4 に示す.

Table 3 The sensor element's output after correcting interaction

\begin{tabular}{c|c|c|c|c|c}
\hline \multicolumn{3}{c|}{ Applied force $[\mathrm{N}]$} & \multicolumn{3}{c}{ Enor [\%RO] } \\
\hline X-axis & Y-axis & Z-axis & X-axis & Y-axis & Z-axis \\
\hline 9.8 & 9.8 & 9.8 & 3.75 & 4.67 & 0.44 \\
\hline 9.8 & 14.7 & 9.8 & 1.10 & 4.08 & 0.78 \\
\hline 14.7 & 9.8 & 9.8 & 3.57 & 4.72 & 0.48 \\
\hline 14.7 & 14.7 & 9.8 & 1.30 & 4.54 & 0.06 \\
\hline 9.8 & 9.8 & 29.4 & 4.17 & 0.62 & 0.64 \\
\hline 9.8 & 14.7 & 29.4 & 1.52 & 0.28 & 0.52 \\
\hline 14.7 & 9.8 & 29.4 & 2.04 & 0.08 & 0.01 \\
\hline 14.7 & 14.7 & 29.4 & 0.08 & 0.49 & 0.08 \\
\hline 9.8 & 9.8 & 49.0 & 4.34 & 3.60 & 0.85 \\
\hline 9.8 & 14.7 & 49.0 & 4.00 & 4.44 & 0.40 \\
\hline 14.7 & 9.8 & 49.0 & 2.48 & 4.45 & 0.70 \\
\hline 14.7 & 14.7 & 49.0 & 0.01 & 4.75 & 0.41 \\
\hline
\end{tabular}

Table 4 The specification for the sensor

\begin{tabular}{c|c|c}
\hline & $\mathrm{X}, \mathrm{Y}$-axis & Z-axis \\
\hline Rated force[N] & 14.7 & 49.0 \\
\hline Accuracy[\%RO] & 5.1 & 2.1 \\
\hline
\end{tabular}

\section{5. 結 言}

本論文では，歪ゲージを受感素子として用いた小型 化が可能な三軸触覚センサを開発し，その有効性を解 析的, 実験的に考察した. その結果, 下記の結論が得 られた。
（1）本研究で提案した構造の触覚センサにより， 三軸方向の力が計測可能であることを有限要 素解析により示した.

(2) 本研究で提案した構造を用いて長さ $25[\mathrm{~mm}]$, 幅 $25[\mathrm{~mm}]$, 高さ $10[\mathrm{~mm}]$ の三軸触覚センサを試 作した.

（3）試作した触覚センサを用いてセンサ表面に働 く垂直力とせん断力を同時に計測できること を実験によって確認した。

提案したセンサは機械的に構造が単純であるため 製作が容易であり，小型化も可能であると考えられる.

今後, ロボット指に分布配置が可能となる大きさに まで本センサの小型化に取り組む予定である.

\section{謝 辞}

本研究は, 文部科学省の事業の一つである, 関西文 化学術研究都市地域知的クラスター創成事業「高度マ ンマシンインターフェイス技術群のネオカデンへの応 用に関する研究」における研究の一環として行った.

\section{文献}

(1) Sasaki, D., et al., Development of Pressure Measurement Type Tactile Soft Sensor for Life Assist Robot, Transactions of the Japan Society of Mechanical Engineers, Series C, Vol. 70, No.689 (2004), pp. 77-82.

(2) Ohka, M., Three-axis Tactile Sensor Capable of Detecting Simultaneously Normal and Shearing Stress Distribution, Journal of the Japan Society of Mechanical Engineers, Vol. 104 (2001), pp. 372-373.

(3) Ohka, M., et al., Sensing Characteristics of an Optical Three-Axis Tactile Sensor Under Combined Loading, Transactions of the Japan Society of Mechanical Engineers, Series C, Vol. 65, No.630 (1999), pp. 602-608.

(4) Ohka, M., et al., Implementation of Experimental Three-Axis Tactile Sensor System Applying Optical Waveguide Plate, Transactions of the Japan Society of Mechanical Engineers, Series C, Vol. 62, No.598 (1996), pp. 164-170.

(5) Tomokuni, N., et al., An Electromagnetic Tactile Sensor for Three-Axis Force Sensing and Its Characteristics, Transactions of the Japan Society of Mechanical Engineers, Series C, Vol. 71, No.703 (2005), pp. 156-163.

(6) Ohka, M., et al., Data processing of tactile information for three-axis tactile sensor, Transactions of the Japan Society of Mechanical Engineers, Series C, Vol. 56, No.531 (1990), pp. 2919-2915.

(7) Kamiyama, K., et al., Applying 3D Force Field Sensation to Robot Finger, Proceedings of the 2005 JSME Conference on Robotics and Mechatronics, Vol. 2005, (2005), 1P1-N-104.

(8) Abe, K., et al., Development of a 3-axis planer force/torque sensor for very small force/torque measurement, Transactions of the Japan Society of Mechanical Engineers, Series C, Vol. 64, No.621 (1998), pp. 172-177. 